\title{
UMA VISÃO ARQUIVÍSTICA SOBRE O REGISTRO DE PROJETOS NO SIE - UNIVERSIDADE FEDERAL DE SANTA MARIA
}

\author{
Gilberto Fladimar Rodrigues Viana ${ }^{1}$ \\ Daniel Flores ${ }^{2}$
}

Resumo: Este trabalho propõe-se a apresentar uma análise e discussão das informações arquivísticas obtidas através do Sistema de Informações para o Ensino (SIE) da Universidade Federal de Santa Maria (UFSM), no âmbito do Centro de Processamento de Dados (CPD) e da Pró-Reitoria de Planejamento (PROPLAN), sobre o módulo de registro e alterações de projetos, cujos tipos são: Ensino, Pesquisa, Extensão e Desenvolvimento Institucional. Também foram realizadas entrevistas com os responsáveis pelo referido sistema. Com base nessas entrevistas e nas demais observações sobre o funcionamento do SIE, foram levantadas algumas situações críticas encontradas e estas foram analisadas no que se refere à autenticidade e à fidedignidade das informações arquivísticas.

Palavras-chave: Autenticidade. Fidedignidade. Registro de produção acadêmica. Patrimônio documental. Informações Arquivísticas.

\section{AN ARCHIVAL VIEW ABOUT THE RECORD OF PROJECTS ON THE SIE - FEDERAL UNIVERSITY OF SANTA MARIA}

\begin{abstract}
This work aims at presenting an analysis and discussion of archival information about register module and alteration of projects. Those projects involve: Teaching, Research, Extension and Institutional Development. The archival information was obtained through the Sistema de Informações para o Ensino (SIE) from the Federal University of Santa Maria (UFSM), Rio Grande do Sul, Brazil, in the scope of its Centro de Processamento de Dados (CPD) and Pró-Reitoria de Planejamento (PROPLAN). There were made interviews with people responsible for the system analyzed. Based on these interviews and observations of the SIE working, it was found and analyzed some critical situations related to authenticity and reliability of the archival information.
\end{abstract}

Keywords: Authenticity. Reliability. Register of academic production. Documentary patrimony. Archival information.

\footnotetext{
${ }^{1}$ Universidade Federal de Santa Maria. vrfgpc@gmail.com.

${ }^{2}$ Universidade Federal de Santa Maria.dfloresbr@gmail.com.

Recebido em: 06/06/2011; aceito para publicação em: 06/07/2012.
} 


\section{INTRODUÇÃO}

O Sistema de Registro e Acompanhamento de Projetos na UFSM foi implantado a partir de 1992, mediante iniciativa dos Gabinetes de Projetos dos oito Centros de Ensino, juntamente com a Pró-Reitoria de Pós-Graduação e Pesquisa e do Centro de Processamento de Dados (CPD) da Universidade.

Atualmente, o sistema é identificado pela sigla SIE, a saber, Sistema de Informações para o Ensino. Este foi desenvolvido a partir do ano 2000 pela equipe do Centro de Processamento de dados da UFSM e elaborado com base nas especificações fornecidas pela Unidade de Coordenação de Programas (UCP) do Ministério da Fazenda, pela Comissão de Informática da Fundação de Apoio a Tecnologia e Ciência (FATEC) da UFSM e pelo Ministério da Educação e Cultura (MEC).

O acesso para lançamento de informações ao SIE é realizado através da rede intranet da universidade mediante prévia instalação do programa, em cada máquina, conforme o interesse do usuário, desde que o computador esteja posicionado próximo a um ponto de rede para conexão. O acesso é restrito aos servidores docentes e técnico-administrativos com vínculo empregatício permanente com a instituição e é realizado através da digitação da matrícula e da senha do usuário na tela chamada de "Controle de acesso".

O presente trabalho consolidou-se a partir da atuação profissional do autor dessa pesquisa, uma vez que é o responsável pelo Gabinete de Projetos (Ensino, Pesquisa, Extensão e Desenvolvimento Institucional) do Centro de Artes e Letras da UFSM, além de desenvolver projetos e ter elaborado duas monografias de especialização com temáticas diretamente relacionadas aos assuntos sobre os quais trata profissionalmente.

Essas funções estão interligadas às dos responsáveis pelo Centro de Processamento de Dados (CPD) da UFSM e, em especial, às atividades dos profissionais de programação envolvidos no SIE, módulo "Acadêmico", item "Produção Institucional", subitem "Registro e Avaliação de Projetos". Além disso, a situação dos documentos arquivísticos digitais é uma temática que envolve todos os profissionais ligados à arquivística, bem como aqueles que atuam especificamente na área de informática e também como dirigentes de uma instituição. Acerca desse cenário de ligação entre áreas, o International Council on Archives - ICA 16 (2005) coloca que:

Os arquivistas devem trabalhar em conjunto com gestores dos sistemas que suportam o desenvolvimento de normas transversais na administração para a interoperabilidade de sistemas, a normalização da gestão da informação e outras iniciativas similares". (ICA 16, 2005, p. 30) 
Essa atuação mostra-se necessária na medida em que as organizações se deparam com um volume elevado de informações arquivísticas em seus bancos de dados, os quais podem, muitas vezes, carecer de um tratamento adequado. Vale-se de Bellotto (2007) quando se fala sobre "fundo arquivo", o qual se associa às informações arquivísticas:

É um universo arqueológico a identificar, balizar, ordenar, descrever e analisar de modo a possibilitar a preservação de sua organicidade, de sua integridade física, e a disseminação de informações extraídas de seus elementos, colocando-as em condições de apreensão e uso plenos (BELLOTTO, 2007, p.13).

Também como forma de fazer essa associação e de buscar uma melhor fundamentação do termo "informações arquivísticas", cita-se Aceves (2011) ${ }^{3}$. Ao falar de "tratamento documental", o autor assim declara:

consiste en un conjunto de operaciones y tareas que se aplican a los documentos en cada una de sus fases del ciclo vital y que tiene como objetivos organizarlos, conservarlos y hacerlos accesibles, manejables y útiles en sus diversos fines (ACEVES, 2011, p.44)

Baseando-se em Brito $(2005)^{4}$, enfatiza-se que as informações arquivísticas têm como objeto a informação, ou seja, é o conteúdo informacional do documento. Também cita-se Lopes (2000) quando se trata da natureza das informações arquivísticas:

a natureza das informações arquivísticas é específica; trata-se de informações registradas em suporte definido, acumuladas por um indivíduo ou por um organismo que é, ao mesmo tempo, produtor e receptor. (LOPES, 2000, p.103)

Tendo em vista tais necessidades para a elaboração desse trabalho, foram considerados os seguintes objetivos específicos:

- identificar o grau de auditagem das informações arquivísticas lançadas no SIE;

- levantar como são tratados, no SIE, o lançamento e as alterações de informações arquivísticas relativas a projetos e como essas informações arquivísticas são tratadas no tocante à sua autenticidade e à sua fidedignidade;

- analisar o gerenciamento de autorizações de acesso ao sistema; e

- verificar como se processa a interação dos usuários com o sistema.

Considerando, ainda, que os dados e as situações dessa investigação foram colhidos à luz de uma realidade na qual o pesquisador se insere e atua (como é o caso desse estudo), bem como seu envolvimento no processo de análise e interpretação desses dados, a abordagem dessa temática foi quantitativa, com aplicação de questionário com

\footnotetext{
${ }^{3} \mathrm{http}: / / 132.248 .242 .3 / \sim$ publica/archivos/libros/bibliotecologia_archivistica_documentacion.pdf

${ }^{4}$ http://dici.ibict.br/archive/00000905/01/AN-2005-12\%5B1\%5्5.pdf
} 
questões fechadas, e qualitativa, em função da análise do questionário aplicado aos docentes do Centro de Artes e Letras da UFSM e da análise das entrevistas do tipo semiestruturada com questões abertas.

Os procedimentos para a elaboração do presente trabalho constituíram-se de entrevistas com os responsáveis a nível gerencial, Servidores Técnico-Administrativos da UFSM, os quais, por questão de sigilo, conforme acordo com os entrevistados, serão denominados entrevistados: entrevistado A, em nível gerencial (coordenador) da PROPLAN; entrevistado B, em nível gerencial (diretor) do Centro de Processamento de Dados; e entrevistado C, em nível gerencial (subchefe/analista) do Centro de Processamento de Dados e, também, do acompanhamento das rotinas de funcionamento do módulo do sistema de registro de alterações de informações arquivísticas. As entrevistas com os responsáveis pelo SIE no CPD e na PROPLAN foram desenvolvidas no decorrer do trabalho. Os dados obtidos nas entrevistas foram compilados conforme as posições convergentes ou divergentes dos entrevistados em relação aos assuntos pertinentes ao sistema, abordados nas entrevistas.

\section{O REGISTRO E AS ALTERAÇÕES DE INFORMAÇÕES ARQUIVÍSTICAS RELATIVAS A PROJETOS NO SIE/UFSM.}

Em relação ao lançamento e às alterações de informações arquivísticas referentes a projetos, no tocante à autenticidade e fidedignidade, esses conceitos foram assim definidos por Heather MacNeil, da Universidade de British Columbia: autenticidade é a "capacidade de um documento arquivístico ser o que diz ser. Refere-se à fidedignidade ao longo do tempo. Está relacionada com a forma de transmissão e as estratégias de preservação e custódia", sustentar os fatos que atesta. Refere-se à autoridade e à confiabilidade de um documento. Está relacionada ao momento da produção do documento"6.

Quanto à autenticidade e fidedignidade desses documentos e à auditagem do histórico das alterações destes no sistema, observa-se que somente é registrada a última ocorrência no documento com as informações arquivísticas de quem acessou o sistema,

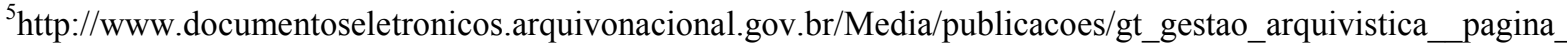
web_corrigido3.pdf

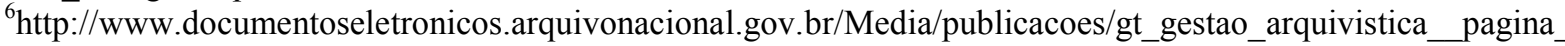
web_corrigido3.pdf
} 
matrícula, hora, dia e máquina/ponto de rede, ou seja, as informações arquivísticas anteriores a essas alterações não são registradas. Inexiste, no SIE, um recurso que permita o rastreamento do que existia anteriormente a tal informação alterada, assim como uma forma de verificar a origem e o responsável pela alteração efetuada. Os entrevistados $\mathbf{B}$ e $\mathbf{C}$ ratificam essa situação, se o entrevistado $\mathbf{B}$ acrescenta, ainda, que o sistema dispõe de dispositivos para esse registro, mas que não são usados em função de problemas de performance do SIE.

Tendo como referência o documento Guide for Managing Electronic Records from an Archival Perspective, um sistema de arquivo, assim descrito conforme texto traduzido para o português de Portugal por Ana Franqueira:

\begin{abstract}
Um sistema de informação desenvolvido com o propósito de armazenar e recuperar documentos de arquivo e organizado para controlar as funções específicas de produção, armazenamento e acesso a documentos de arquivo, para salvaguardar a sua autenticidade e fidedignidade (ICA 16, 2005, p.14).
\end{abstract}

A análise desse documento deixa claro como o sistema deve ser para garantir a autenticidade e a fidedignidade dos documentos gerados. Cabe salientar que, quando se refere a sistema, aqui, trata-se do SIE, módulo de registro e alterações de projetos.

Quanto à fidedignidade, Rondinelli (2005, p.65) contribui afirmando que essa é uma das características do documento que lhe dá sustentação:

O grau de controle dos procedimentos de criação de um documento eletrônico arquivístico também se constitui em elemento de fidedignidade desse documento. Considerando que tais procedimentos envolvem o controle do documento desde a sua criação até sua destinação final.

No caso do sistema de registro e alteração de projetos, pode-se dizer que o caráter fidedigno do documento é sustentado pela chancela de quem aprovou tais situações através de um fluxo hierárquico de autorizações.

Quanto à autenticidade, inicialmente traça-se um paralelo das questões pertinentes ao sistema, tendo como referência documentos analógicos e digitais e, para tanto, recorre-se a Ferreira (2006, p.50), quando este afirma que:

No contexto digital, os problemas relacionados com a autenticidade são em tudo semelhantes aos do mundo analógico. Contudo, a simplicidade com que alterações podem ser introduzidas, a rapidez com que estas podem ser disseminadas e a dificuldade inerente à sua detecção tornam o problema sensivelmente mais complexo.

O autor salienta alguns fatores de vulnerabilidade que colocam um sistema sob risco e, por sua vez, os documentos gerados a partir deste, ou seja, o problema se torna muito mais complexo do que com documentos convencionais (analógicos). 
Cita-se também Rocha e Silva (2007, p. 113-124), que evidencia a preocupação dos profissionais da arquivologia em relação à autenticidade das informações arquivísticas:

Há necessidade de gerenciar este acervo digital de forma a garantir a autenticidade e acesso de longo prazo dos documentos arquivísticos, pois estes servem de prova para assegurar o exercício dos direitos do cidadão e a transparência das ações das instituições, bem como de fonte para a pesquisa histórica e científica.

Seguindo a linha de fundamentação dos procedimentos que garantem a integridade das informações arquivísticas de um sistema, cita-se CONArq (2006, p.35):

O sistema de gestão arquivística deve prever controles de acesso e procedimentos de segurança que garantam a integridade dos documentos. Entre esses procedimentos, podem-se destacar o uso de controles técnicos e programáticos, diferenciando tipos de documentos, perfis de usuários e características de acesso aos dados, e a manutenção de trilhas de auditoria e de rotinas de cópias de segurança.

Associa-se a questão da prevenção como sendo um dos métodos que contribui para a idoneidade do sistema, ou seja, ser dotado de crédito e confiança no que expressa. Nesse sentido, Rondinelli (2005, p.65) afirma que a prevenção:

[...] inclui limitação de acesso à tecnologia que envolve o sistema e definição de regras de workflow. A limitação de acesso consiste na criação de privilégios de acesso por meio de senhas, cartões magnéticos, impressões digitais etc. As regras de workflow definem o que será feito e como será feito, de tal maneira que procedimentos administrativos e documentários estejam integrados.

Portanto, entende-se que a prevenção deva ocorrer através da observância de estudos como do ICA16 (2005, p.32), que estabelecem as condições que asseguram a autenticidade e fidedignidade dos documentos, as quais devem ser consideradas em relação ao sistema.

Outra situação que também contribui para o alcance do objetivo específico sobre autenticidade e fidedignidade é quanto às trilhas de auditoria relativas ao sistema. Para isso, recorre-se à informação dos entrevistados $\mathbf{B}$ e $\mathbf{C}$, que dizem não existir histórico das alterações de informações arquivísticas no sistema SIE e afirmam não existir trilha de auditoria ou outro mecanismo similar, conforme já relatado na situação anteriormente referida. É salientado pelo entrevistado B que a instituição se ressente pela falta de um gerente de módulo de registro de projetos que decida sobre quais as informações arquivísticas devem ser gravadas.

A partir das declarações dos entrevistados, e também do acompanhamento das rotinas do sistema relativos ao histórico de alterações, constata-se que os requisitos recomendados como obrigatórios para um sistema, estabelecidos através do documento elaborado pelo Conselho Nacional de Arquivos - Conarq intermediado pela Câmara 
Técnica de Documentos Eletrônicos, denominado Modelo de Requisitos para Sistemas Informatizados de Gestão Arquivística de Documentos - e-ARQ Brasil, quando dizem que "A trilha de auditoria consiste num histórico de todas as intervenções, ou tentativas de intervenções, feitas no documento e no próprio Sistema Informatizado de Gestão Arquivística de Documentos - SIGAD”, não são aplicados, assim como os modelos de requisitos indicados pela Modelo de Requisitos para a Gestão de Arquivos Eletrônicos Moreq.

Nessa linha de argumentação, recorre-se a Rondinelli (2005, p. 66) ao afirmar que o estabelecimento de um método de verificação contribui para a idoneidade do sistema, citando a trilha de auditoria como método de verificação, quando discorre que:

[...] este consiste no estabelecimento de uma trilha de auditoria, ou seja, de um mecanismo que permite registrar todas as intervenções feitas no documento, as quais incluem modificar, apagar, acrescentar ou simplesmente ver o documento.

Recorre-se também a Rocha e Silva (2007, p. 115) para destacar a preocupação dos profissionais da área de arquivologia em relação à observância dos requisitos que devem ser seguidos como forma de garantia da integridade das informações arquivísticas. Segundo os autores, "O grande desafio apresentado pelos documentos digitais é a garantia da produção de documentos confiáveis e a manutenção de sua autenticidade e acesso de longo prazo".

Já Innarelli (2009, p. 69), quando fala dos dez mandamentos da preservação digital, no de número dez, que trata das "Garantias a autenticidade dos documentos digitais", orienta que para esse fim é necessário estabelecer critérios e selecionar ferramentas e, em especial, a trilha de auditoria, afirmando que "as trilhas de auditoria de um sistema têm como função principal o rastreamento de todas as intervenções feitas no documento digital, a partir de um conjunto de informações registradas"

Ainda conforme Innarelli (2009), destacam-se algumas verificações: de acesso, de alteração, de visualização, de exclusão e de trâmite, pelas quais a trilha de auditoria é responsável. Assim, entende-se que as verificações citadas estão associadas às situações do sistema de registro de projetos, ao enfatizar que "as trilhas de auditoria funcionam como um $\log$ de sistema, armazenando todos os eventos relativos aos documentos registrados. Esses eventos são fundamentais para a verificação da autenticidade do documento digital” (INNARELLI, 2009, p.69) 
Ainda quanto à trilha de auditoria, citam-se os estudos do ICA16 (2005) e a aplicação da norma ISO $15489-2^{7}$, bem como os requisitos descritos na e-ARQ Brasil (2006), quando se relacionam estes como um dos quesitos a serem observados quando se trata da autenticidade das informações arquivísticas do sistema. A partir das constatações deste no tocante à autenticidade e à fidedignidade dos documentos, confrontando-se com o que é definido através de normativas, de requisitos e, também com o que é escrito por estudiosos sobre o assunto, leva-se a ponderar que, para uma melhor eficiência do sistema, essas questões precisam ser mais bem tratadas.

\section{O GERENCIAMENTO DAS AUTORIZAÇÕES DE ACESSO AO SISTEMA}

Quanto ao gerenciamento das autorizações de acesso ao sistema de registro de projetos, tanto o entrevistado $\mathbf{B}$ como o entrevistado $\mathbf{C}$ admitem a fragilidade e as deficiências desse gerenciamento e citam situações que ocorrem frequentemente. Também associam essa situação à questão de segurança da informação.

O entrevistado $\mathbf{C}$ relata uma situação que acontece com frequência e que diz respeito ao acesso ao sistema/aplicações por pessoas que não mais ocupam funções exercidas anteriormente e que tinham responsabilidade de gerenciar essas aplicações.

Como é referido pelos entrevistados, a situação de fragilidade e deficiência do gerenciamento das autorizações de acesso ao sistema se deve ao não tratamento, de forma adequada, dessa questão por parte dos responsáveis pelo sistema e pelos outros setores envolvidos indiretamente com o mesmo. Nesse caso, por exemplo, o setor de recursos humanos da instituição.

O controle dos grupos de usuários aptos a serem credenciados com função de tramitar projetos acontece de maneira informal, bastando uma solicitação à Central de Atendimento ao Usuário (CAU), sem o necessário acompanhamento para verificar se os usuários com autorizações hierárquicas de tramitação de projetos estão exercendo ou não a função de chefia e/ou são membros de comissões autorizadas para tais acessos. Uma vez que a instituição conta com um documento burocrático oficial, uma portaria, classificada como um tipo documental, sistematizada no SIE, a expedição desse documento poderia ser integrada ao sistema de senhas, com vistas a facilitar as

\footnotetext{
${ }^{7}$ http://www.tavanir.org.ir/tech-doc/nezam/iso_15489-2.pdf
} 
autorizações a quem venha a exercer funções que demandem responsabilidades de tramitação, e também para impedir usuários que já não ocupam mais funções que detenham tais responsabilidades ao acessarem funções restritas a quem esteja investido na função designada ou nomeada.

Quanto a essa questão, reporta-se a Santos (2005) quando trata, de uma forma bem objetiva, sugerindo que a instituição, além de estabelecer normas e critérios para autorizações de usuários, deve desenvolver atividades de sensibilização sobre as implicações da vulnerabilidade do sistema se não forem seguidas as normas de segurança. Quanto a isso, assim discorre o referido autor:

O melhor caminho para prevenir os riscos de segurança relativos aos usuários autorizados é o estabelecimento de um ambiente de trabalho que induza á lealdade e cumplicidade dos funcionários ou usuários autorizados com as políticas e atividades da instituição. Além disso, novos funcionários devem passar por treinamentos que abranja o uso de equipamentos e procedimentos de segurança (SANTOS, 2005, p.129).

De outra parte, Innarelli $(2009$, p. 60) explicita que o controle de acesso é um dos critérios para garantia da autenticidade dos documentos digitais, afirmando que: "deve restringir o acesso ao acervo digital de forma a permitir que somente os usuários autorizados, nos diversos níveis de autorizados, nos diversos níveis de autorização, possam interagir com o acervo em questão”. Além disso, na e-ARQ Brasil (2006), no item 6, que trata de segurança de sistema no subitem 6.2, que trata do controle de acesso, são estabelecidos os requisitos obrigatórios além de outros que garantam a integridade do sistema sob o aspecto de segurança.

Portanto, mesmo não se tomando essa afirmação de forma dogmática, tendo em vista haver outras posições sobre o assunto, considera-se que o gerenciamento das autorizações de acesso ao sistema mostra-se inconsistente sob o ponto de sustentação de legitimidade das pessoas que estão autorizadas a ter acesso ao sistema.

\section{PROCESSOS DE INTERAÇÃO DOS USUÁRIOS COM O SISTEMA}

Considera-se, nessa seção, o processo de interação dos usuários com o sistema a partir das seguintes situações: a situação dos manuais de registro e alterações de projetos, o serviço de auxílio ao usuário denominado no CPD de Central de Atendimento ao Usuário (CAU) e a situação do sistema em operação via intranet. 


\subsection{Situação do manual de registro e alterações de projetos}

Ao tratar-se da situação dos manuais do sistema de registro e alteração de projetos sob o enfoque de interação dos usuários com o sistema, foram consideradas as entrevistas concedidas pelos responsáveis pelo CPD. Quanto a esse enfoque do trabalho, o entrevistado $\mathbf{B}$ falou da falta desses manuais, e o entrevistado $\mathbf{C}$ disse que existem manuais, porém com deficiências, levantando, ainda, outro problema: a falta de normativas em relação ao sistema de registro de projetos. Em relação a esse assunto, foi editada recentemente uma resolução que regulamenta o sistema de registro e alterações de projetos vigentes, que está defasado.

Diante desses depoimentos, constatou-se que o manual sobre registro e alteração de projetos não está disponível no sistema, e sim na página da UFSM, denominado Div Rel (divisão de relacionamento) ${ }^{8}$. Porém, não aparece de forma clara, ou seja, o usuário não tem nenhuma forma de indicação/localização exata de onde encontrar o manual de registro e alterações de projetos.

A ausência de manuais acarreta transtornos aos usuários do sistema, mesmo para aqueles que já o operam há mais tempo, pois usam o módulo registro esporadicamente. A situação se agrava à medida que, nos últimos anos, tem aumentado o número de novos servidores docentes que ingressam na instituição e que não contam com informações ou manuais que lhes permita usar o sistema de forma adequada para registro de projetos. Considerando-se que o interesse em registrar projetos por parte desses docentes é significativo, visto que estes já possuem, em sua formação acadêmica, a cultura do desenvolvimento de projetos, intensifica-se a necessidade da existência de manuais adequados e atualizados.

Somam-se, a essa questão, a cultura institucional de financiar projetos de ensino, pesquisa e extensão e, ainda, a de incentivar que os projetos da instituição também concorram em editais externos, de agências de fomento, tanto públicas quanto privadas.

Outro fator a ser considerado, e que muitos docentes desconhecem, é a repercussão do quantitativo de projetos nos indicadores institucionais, tanto interna como externamente.

Procurou-se uma normativa que atendesse à situação ora analisada, que tem relação com a questão da ausência de manuais do sistema de registro e alterações de

\footnotetext{
${ }^{8} \mathrm{http} / / /$ w3.ufsm.br/divrel/index.php?id=manuais
} 
projetos e, então, encontrou-se no Manual de Certificação para Sistemas de Registro de Eletrônico em Saúde ${ }^{9}$, no capítulo "requisitos de conformidade, no item requisitos de segurança 1 no item NGS1.09 - documentação", no qual consta que a presença de manuais é um requisito obrigatório e onde, também, são definidos os tipos de relatórios. Para essa análise destacam-se os manuais: do usuário; do administrador e do operador; e de práticas de segurança. Outra questão importante tratada nesse documento é a obrigatoriedade da informação sobre qual versão o manual se refere, sendo que essa informação deve ser enunciada de forma clara e no início do documento.

\subsection{Serviço de auxílio ao usuário}

Nesse aspecto, constatam-se algumas situações que se considera importantes, colhidas dos entrevistados sobre o serviço de auxílio ao usuário, CAU, dentro do processo de interação do SIE com aqueles que o utilizam, no que se refere às alterações e às dúvidas sobre a operação do sistema de registro e alterações de projetos.

Com referência ao serviço citado, o entrevistado $\mathbf{B}$ disse que o gerenciamento de senhas, esclarecimentos de dúvidas e relatórios estão sob a responsabilidade do CAU, e que esse serviço se desenvolve através da prática diária dos atendentes (bolsistas) que respondem aos pedidos de esclarecimentos por parte dos usuários. O entrevistado $\mathbf{C}$ afirmou que a maioria das alterações no sistema de registro de projetos se dá por solicitação de usuários lotados na PROPLAN, nos Gabinetes de Projetos e no próprio CPD.

Ainda quanto à interação dos usuários com o sistema, constatou-se que o CPD dispõe de CAU, sendo que essa central também tem a incumbência de responder informalmente às dúvidas (problemas) e aos questionamentos que os usuários enfrentam cotidianamente no uso do sistema. Verificou-se, também, que as dúvidas/problemas, uma vez respondidas e/ou solucionadas, não são repassadas aos demais usuários do sistema, ou seja, rotinas e telas são alteradas, suprimidas e acrescidas, de modo que essas modificações só serão percebidas por outros usuários à medida que estes acessarem o sistema e se depararem com limitações/alterações antes não encontradas.

Por outro lado, observou-se, ainda, a dificuldade do usuário em assimilar as rotinas de telas com recursos pouco convencionais que geram uma indisposição desse

\footnotetext{
${ }^{9}$ http://www.saudedireta.com.br/files/Manual do CFM e SBIS.pdf
} 
usuário em relação ao sistema. Desse modo, o este pode ser classificado como sendo pouco amigável. Essa consideração foi feita a partir das respostas dos usuários quando consultados sobre a sequência dos procedimentos para o lançamento das informações do registro do projeto no sistema. Aproximadamente $60 \%$ se mostraram insatisfeitos com sistema, englobando as opções:regular, ruim e sem resposta.

Em relação às situações acima relatadas, destacam-se as contribuições do ICA 16 (2005, p. 36): "Habitualmente, os grandes sistemas de informação que são críticos para actividades da organização, não operam mais do que alguns dias sem manutenção. Um grande número de problemas pode ocorrer". Esse documento ainda enfatiza que as alterações no sistema afetam os requisitos que dão integridade aos documentos, ao afirmar que:

\footnotetext{
Ao mesmo tempo devem ter em conta as actualizações da documentação do sistema porque muitas das correções nele realizadas podem ter sido feitas em situações de emergência, altura em que não sobre tempo para elaborar documentação apropriada sobre as alterações introduzidas (ICA 16, 2005 p.37).
}

Para a solução desse problema, entende-se que o sistema deveria dispor de um mecanismo de alerta, um dispositivo de ajuda. Mas o principal problema a ser resolvido deveria ser a atualização e a melhor localização do manual de registro e de alteração de projetos.

\subsection{Operação do sistema via Intranet}

Outro aspecto a ser considerado em relação à interação dos usuários com o sistema é o fato deste operar via intranet, fator que também dificulta o processo de interação sistema $\mathbf{x}$ usuários. Essa consideração baseia-se nas respostas ao questionário aplicado aos usuários quando perguntados sobre o seu interesse de que seus projetos registrados no sistema pudessem ser acessados através da Web. Setenta e sete por cento $(77 \%)$ dos usuários manifestaram interesse nesse tipo de acesso englobando as opções mencionadas anteriormente, os quais, atualmente, utilizam o sistema e já tem a cultura de trabalhar no ambiente $W e b$, e que costumam desenvolver atividades relacionadas à instituição fora de seu ambiente de trabalho, enquanto que, em se tratando de registro e alterações de projetos, esses procedimentos somente podem ser realizados dentro da instituição. 
Quanto ao fato de o sistema operar somente intranet, passa-se a relatar, de forma resumida, alguns depoimentos dos entrevistados $\mathbf{B}$ e $\mathbf{C}$ em relação a essa situação.

O entrevistado $\mathbf{B}$ afirmou que, atualmente, o sistema está obsoleto quanto ao acesso, estando em fase de estudo uma nova arquitetura do sistema, provavelmente Java, ou outra tecnologia atualizada. Esse entrevistado salientou que se faz necessária a priorização dos aplicativos referentes a projetos, quando for possível a utilização do suporte via $\mathrm{Web}$.

Para o entrevistado $\mathbf{C}$, o fato de o sistema de registro de projetos ainda operar somente via intranet é ruim. Acredita que quando o sistema SIE operar via Web, o procedimento de registro de projetos não terá como prioridade operar todos os aplicativos via $W e b$, salvo aplicações como a avaliação de projetos e atualização de participantes em projetos. Em função dessa posição deduz-se que o déficit operacional do sistema irá persistir, mesmo que o aplicativo venha ser disponibilizado via $W e b$.

Em contrapartida a essa posição, recorre-se ao estudo do ICA 16 (2005, p. 55), quando diz:

Utilizadores externos podem por vezes ser autorizados a aceder a esses documentos ainda em fase da produção, quer directamente no sistema ou indiretamente através de serviços fora de linha ou de sistema de informação especificamente concebidos para esse efeito.

Dessa forma, por analogia, entende-se que essa é uma alternativa viável e necessária a ser aplicada, considerando-se a necessidade dos usuários de operarem o SIE via Web, mesmo sendo conflitante com a posição dos administradores do sistema de registro projeto em viabilizar o acesso via $W e b$.

\section{CONSIDERAÇÕES FINAIS}

Acompanhando o tratamento das informações arquivísticas referentes ao registro e às alterações de projetos lançadas no SIE e, também, com base nos depoimentos dos entrevistados, constatou-se uma situação bastante atípica em relação aos requisitos que viabilizam e sustentam a autenticidade e a fidedignidade dos documentos, deduzindo-se que o sistema pode estar comprometido em relação a essas duas características. Corroboram essa afirmação as seguintes constatações: $1^{\circ}$ ) há debilidade/falta de controle oficial de grupos, categorias e/ou níveis de acesso ao sistema; $2^{\circ}$ ) há indisponibilidade 
do registro do histórico das intervenções ou alterações de informações arquivísticas no sistema, ausência de trilha de auditoria. Para haver conformidade com esse aspecto, teriam que ser observados estudos do ICA16 (2005) e aplicada a norma ISO 15489-2 ${ }^{10}$, bem como os seguintes requisitos descritos no e-ARQ Brasil:

O rastreamento dos documentos em trilhas de auditoria é uma medida de segurança que tem por objetivo verificar a ocorrência de acesso e uso indevidos aos documentos. $\mathrm{O}$ grau de controle de acesso e o detalhamento do registro na trilha de auditoria dependem da natureza do órgão ou entidade e dos documentos produzidos (CONArq, 2006, p.36).

Portanto, quanto aos critérios que asseguram idoneidade aos documentos, segundo Rondinelli (2005), Rocha (2007) e também Ferreira (2006), acredita-se que o SIE apresenta-se seriamente comprometido.

Através do acompanhamento do gerenciamento das autorizações de acesso ao sistema, observou-se que esse gerenciamento é realizado de maneira informal pelo serviço de auxílio ao usuário, denominado CAU, que é operado por bolsistas e que, na operação desse sistema, não existe nenhum tipo de protocolo ou registro de solicitação de ativação ou desativação de autorizações de senhas para acesso ao mesmo. Também, conforme depoimento dos entrevistados, a fragilidade $\mathrm{e}$ as deficiências do gerenciamento de senhas são percebidas e referem-se a situações em que as pessoas já não ocupam cargos de chefia e, apesar disso, continuam com a sua senha autorizada para tramitar documentos na condição de responsáveis pela subunidade.

Outra situação citada pelos entrevistados é a falta de normatização na definição de grupos de usuários e suas respectivas funções hierárquicas no sistema, ou seja, maior clareza sobre os tipos de funções e autorizações que lhes são pertinentes. Considerando o que afirmam Santos (2005), Innarelli (2009) e CONArq (2006) quando se trata de normas de segurança para o controle do acesso ao sistema:

\footnotetext{
Um sistema de gestão arquivística de documentos deve garantir que os usuários não autorizados não tenham acesso aos documentos classificados, isto é, submetidos às categorias de sigilo previstas em lei, bem como aqueles que são originalmente sigilosos. O acesso aos metadados dos documentos sigilosos depende de regulamentação interna do órgão ou entidade. (CONArq, 2006, p.35)
}

Em relação às autorizações de acesso ao sistema, pode-se afirmar que, pelo fato de as portarias serem gerenciadas por essa ferramenta de gestão, elas respaldariam automaticamente os acessos ao sistema.

\footnotetext{
${ }^{10}$ http://www.tavanir.org.ir/tech-doc/nezam/iso_15489-2.pdf
} 
No tocante ao processo de interação dos usuários com o sistema, inicialmente considerou-se a questão do manual de registro e alterações de projetos. Quanto a esse aspecto, a situação mostra-se insólita, uma vez que, segundo informações fornecidas pelos entrevistados responsáveis pelo gerenciamento do sistema e acesso à página da UFSM, o manual de registro de projetos não é disponibilizado aos usuários no sistema (SIE), e sim no site da instituição, que está desatualizado. Isso ocorre em razão das frequentes modificações/alterações nas rotinas de tela e a outras questões congêneres que são feitas pelo CPD para atender situações específicas, de forma a sanar dificuldades encontradas por parte de um determinado usuário. Nesse sentido, cita-se o Manual de Certificação para Sistemas de Registro de Eletrônico em Saúde, que estabelece regras rígidas em relação a manuais. O problema verificado está na falta de divulgação dessas alterações para os demais usuários, os quais encontram as mesmas dificuldades na operacionalização do sistema. Em relação a esse problema, recorre-se, mais uma vez, aos estudos do ICA16 (2005) ao afirmar que:

\begin{abstract}
Ao mesmo tempo devem ter em conta as actualizações da documentação do sistema porque muitas das correções nele realizadas podem ter sido feitas em situações de emergência, altura em que não sobre tempo para elaborar documentação apropriada sobre as alterações introduzidas (ICA 16, 2005 p.37).
\end{abstract}

Quando se refere ao desafio de se manter um banco de dados íntegro em relação aos quesitos que dizem respeito às normas e à legislação arquivísticas vigente, cita-se Rocha e Silva (2007, p. 116): “O grande desafio apresentado pelos documentos digitais é a garantia da produção de documentos confiáveis e a manutenção de sua autenticidade e acesso de longo prazo".

Portanto, faz-se necessário que sejam mantidas adequadamente as informações arquivísticas constantes dos registros dos projetos e armazenadas no banco de dados da UFSM, o qual se constitui como patrimônio documental da instituição, já que a prática institucional é registrar projetos. Tal prática acontece há aproximadamente 25 anos através do sistema, e é estimulada pela administração Central, que considera o compromisso institucional que envolve o Ensino, a Pesquisa e a Extensão. Essa manutenção adequada também é necessária devido às implicações orçamentárias e administrativas na instituição, assim como no âmbito do MEC. O registro do que do foi, do que é e do está planejado para ser desenvolvido na instituição no que se refere ao Ensino, à Pesquisa e à Extensão está nesse sistema. Por esses motivos é que os dirigentes da instituição e seus usuários devem zelar para que esse sistema seja dotado de garantias que viabilizem a fidedignidade e a autenticidade das informações arquivísticas armazenadas no sistema, e garantam acessibilidade à sociedade e ao meio acadêmico, ressaltando-se que o banco de projetos da instituição também é considerado como patrimônio documental, amparando-se no que diz a Constituição Federal de 1988, em seu artigo 216:

Constituem patrimônio cultural brasileiro os bens de natureza material e imaterial, tomados individualmente ou em conjunto, portadores de referência à identidade, à ação, à memória dos diferentes grupos formadores da sociedade brasileira, nos quais 
se incluem: I -as formas de expressão; II -os modos de criar, fazer e viver; III -as criações científicas, artísticas e tecnológicas; IV - as obras, objetos, documentos, edificações e demais espaços destinados às manifestações artístico culturais; V -os conjuntos urbanos e sítios de valor histórico, paisagístico, artístico, arqueológico, paleontológico, ecológico e científico (CONSTITUIÇÃO DA REPÚBLICA FEDERATIVA DO BRASIL, 1988).

Desse modo, espera-se que as considerações aqui apresentadas possam servir de subsídio para que os administradores do sistema possam proceder a algumas modificações que julgarem necessárias para torná-lo mais eficiente.

\section{REFERÊNCIAS}

ACEVES, M. R. La archivística: ¿ciencia o técnica?. In: ROJAS, Miguel Angel Rendón (coord). Bibliotecología, archivística, documentación: intradisciplina, interdisciplina o transdisciplinariedad [et. al.]. - México: Centro Universitário de Investigaciones Bibliotecológicas, 2011. p. 39-49.

BELLOTTO, H. L. Arquivos permanentes: tratamento documental. 4. ed. rev. ampl. Rio de Janeiro: FGV, 2007.

CONARQ, Conselho Nacional de Arquivos; Câmara Técnica de Documentos Eletrônicos. Modelo de requisitos para sistemas informatizados de gestão arquivística de documentos: e-ARQ Brasil. 2006. Disponível em: $<$ http://www.conarq.arquivonacional.gov.br/Media/publicacoes/earqbrasilv1.pdf $>$. Acesso em: 08 out. 2008 .

FERREIRA, M. Introdução à preservação digital: conceitos, estratégias e actuais consensos. Guimarães, Portugal : Escola de Engenharia da Universidade de Minho, 2006.

INTERNATIONAL COUNCIL ON ARCHIVES. Committee on current records in a electronic environment. Electronic records: workbook for archivist. Paris (France): ICA, 2005. (ICA Studies 16). Disponível em:

$<$ http://www.ica.org/10801/studies-and-case-studies/ica-study-n16-electronic-records-aworkbook-for-archivists.html>. Acesso em: 08 out. 2008.

INNARELLI, H. C. Preservação digital e seus dez mandamentos. In: SANTOS, Vanderlei Barbosa dos (org). Arquivística: temas contemporâneos. Brasília: SENACDF, 2007. p. 21-71.

LOPES, L. C. A nova arquivística na modernização administrativa. Rio de Janeiro : [s. n.], 2000.369 p. 
MOREQ. Especificação Moreq. Modelo de Requisitos para a Gestão de Arquivos Eletrônicos. Bruxelles - Luxembourg, [s. n.] 2001. Disponível em: http://europa.eu.int/idabc/servlets/Doc?id=16849. Acesso em: 08 out. 2008.

ROCHA, Cláudia Lacombe; SILVA, Margareth da. Padrões para Garantir a Preservação e o Acesso aos Documentos Digitais. Acervo, Rio de Janeiro, v. 20, n. 1-2, p. 113-124, jan./dez. 2007.

RONDINELLI, R. C. Gerenciamento arquivístico de documentos eletrônicos: uma abordagem teórica da diplomática arquivística contemporânea. 4. ed. Rio de Janeiro: FGV, 2005. 160p.

SANTOS, V. B. dos. Gestão de documentos eletrônicos: uma visão arquivística. 2. ed. Brasília: ABARQ, 2005. 223p.

UNIVERSIDADE FEDERAL DE SANTA MARIA. Sistema de Informações para o Ensino: banco de dados. 